\title{
The Histocompatibility System in Juvenile, Insulin-Dependent Diabetic Multiplex Kindreds
}

\author{
Jose Barbosa, Richard King, and Harriet Noreen, The Departments of Medicine \\ and Pathology and Laboratory Medicine, University of Minnesota, \\ Minneapolis, Minnesota 55455 \\ Edmond J. Yunis, The Department of Pathology, Harvard University Medical \\ School, Boston, Massachusetts 02115
}

\begin{abstract}
A B S T RACT We have histocompatibility (HLA) genotyped 24 families with two or more juvenile, insulin-dependent, ketosis-prone diabetic siblings. This criterion for family selection was used to obtain a homogeneous form of diabetes within a sibship, because diabetes appears to be a genetically heterogeneous disease. 58 diabetic and 53 nondiabetic sibs and 40 parents were studied. $55 \%$ of the diabetic pairs were concordant for both HLA haplotypes (expected $25 \%$ ), $40 \%$ were concordant for one haplotype (expected 50\%), and 5\% were discordant for both haplotypes (expected 25\%). These values are significantly different from the expected values $(P<0.001)$. On the other hand, the inheritance of haplotypes among the nondiabetic sibs in these families was not significantly different from the expected mendelian segregation.
\end{abstract}

When comparing 20 pairs of HLA identical (sharing two haplotypes) with 15 pairs of haploidentical (sharing one haplotype) diabetic sibs for the intrapair difference in age of onset of disease, we found that the HLA identical sibs were significantly more concordant for age of onset ( $3.9 \mathrm{yr}$ difference) than the haploidentical $(7.3 \mathrm{yr}$ difference) $(P<0.05)$. The same type of analysis for the difference in seasonal incidence in months revealed that the HLA identical sibs were more concordant (1.8 mo difference) than the haploidentical sibs $(3.2$ mo difference) $(P<0.025)$. Furthermore, the HLA identical diabetic sibs were more likely to develop diabetes in the winter months $(78 \%)$ than the haploidentical diabetic sibs $(21 \%)$.

No particular HLA haplotype or antigen seemed to be associated with any particular clinical feature.

This work was presented in part to the 36th National Meeting of the American Diabetes Association, San Francisco, 20-22 June 1976, and the 1st Congress of HLA and Disease, Paris, 23-25 June 1976.

Received for publication 18 February 1977 and in revised form 15 July 1977.
These data are compatible with the theory of genetic heterogeneity of juvenile, insulin-dependent diabetes. It is suggested that there are one or more diabetes response genes in the HLA region playing an important role in the pathogenesis of juvenile, insulin-dependent diabetes in the families studied here. It is, however, possible that other genes, not associated with the HLA complex, may play an etiologic role in some cases of juvenile, insulin-dependent diabetes, resulting in lack of association between HLA and some forms of diabetes.

\section{INTRODUCTION}

Recent studies of juvenile, insulin-dependent diabetes mellitus (JIDD) ${ }^{1}$ have pointed out the importance of hereditary factors in this disease. Uncertainty remains about the mode of inheritance, however, and all known genetic mechanisms have been suggested (1). Evidence from diabetic twin studies has hinted at important environmental factors in the pathogenesis of at least some cases of JIDD (2), and findings of associations between histocompatibility (HLA) antigens and JIDD have strengthened the genetic theory of the disease. Associations of HLA antigens B8 (3-5), BW15 (3,4-6), CW3 (7), and DW3 (8) have been described with JIDD, and it has been postulated that a gene (or genes) linked to and in disequilibrium with loci B and D of the HLA complex is important in the pathogenesis of this form of diabetes (4). Similar findings have not been found with typical adultonset, insulin-independent diabetes, confirming the belief that these two forms of diabetes are genetically different. Maturity-onset type of diabetes in the young, another form of insulin-independent diabetes, may be associated with HLA antigens (9), although opposing evidence has been reported (10).

${ }^{1}$ Abbreviations used in this paper: HLA, histocompatibility; JIDD, juvenile insulin-dependent diabetes mellitus. 
HLA studies have not only confirmed the previously known clinical and biochemical evidence (1) that diabetes mellitus is a genetically heterogeneous disease, but have also suggested that JIDD itself is heterogeneous. In fact, population studies have shown that subjects with $\mathrm{B} 8$ and BW15 B-locus genotype have (a) higher relative risk for the development of JIDD $(11,12),(b)$ earlier onset of disease (12), and (c) lower plasma concentrations of C-peptide (12), a presumed indication of more severe $\beta$-cell damage, than subjects carrying either B8 or BW15. An association between the presence of $\mathrm{BW} 15$ and higher insulin antibody titers $(12,13)$, a possible indicator of more severe JIDD $(12,14)$, has also been reported.

The identification of a patient sample likely to harbor genetically homogeneous JIDD would be of interest. The study of individual families with higher intrasibship prevalence of diabetes may be informative because genetic homogeneity of the disease is more likely in the affected sibs. Because of the previous work suggesting an association of HLA and diabetes, studies of HLA antigens in such families may allow a better understanding of the genetic mechanisms involved. HLA antigens are determined by alleles at four closely linked loci (A, B, C, and D). The set of alleles at the four loci on a single chromosome determines the haplotype, and an individual inherits two haplotypes, one from each parent. Susceptibility to diabetes associated with HLA antigens may result in concordance between HLA and diabetes. Because HLA haplotypes differ among families, an association between a specific haplotype and diabetes may be more easily detectable by studying families with many affected individuals.

In a recent study of HLA haplotypes in $\mathbf{1 7}$ families with several cases of JIDD per sibship, the frequency of HLA haploidentity (sharing of one or two HLA haplotypes) between the diabetic siblings within each sibship was found to be about $90 \%$, as opposed to the expected $75 \%$ (4). Another study of 10 kindreds with JIDD did not confirm these findings (15). The HLA haplotypes of the parents were not given in the first of these studies, and the haplotypes of the healthy siblings were not available in either report. Furthermore, control, nondiabetic families were not included in these reports. Inasmuch as the study of the nonaffected siblings affords the best control population in family analysis of disease, we have studied the HLA haplotypes (A and B loci) in 24 nearly complete sibships with two or more cases of JIDD and the parents. 92 nondiabetic families served as controls.

\section{METHODS}

Clinical material. A total of 24 diabetic multiplex kindreds were studied. All were Caucasians and $90 \%$ were of Northern European ethnic background. In 16 families there were two diabetic siblings, including 1 family with two diabetic sibs in two consecutive generations (A. P.), and 1 family with two diabetic sibs in two consecutive generations and a single diabetic (deceased) in a third generation (S. Ros.). Eight families included three diabetic sibs, but in two the third diabetic sib was deceased or unavailable. Of 61 known diabetics in these families, including 2 that were deceased, 58 were tissue typed (95\%). 53 of 74 nondiabetic sibs were studied $(71 \%)$. Sibship size ranged from 2 to 12 , and the mean number of sibs per family was 5 . 40 of 48 parents were studied $(83 \%)$; 5 fathers were deceased and 3 were unavailable. The age of the diabetic sibs was $22.8 \pm 10.2($ mean \pm SD) $y r$ and that of the nondiabetics $22.7 \pm 12.0 \mathrm{yr}$. $51 \%$ of the diabetics and $58 \%$ of the nondiabetics were females.

All diabetics were insulin-dependent and ketosis-prone, with the onset of the disease at $11 \pm 8 \mathrm{yr}$ of age. The onset of diabetes was before the age of 40 in all patients. All families filled out a questionnaire for each diabetic that included the following information: the age and month of onset of diabetes, history of infections during 3 mo before the onset of the disease, ethnic background, family history of diabetes, and personal and family history of other diseases. The onset of polydipsia or polyuria, as usually recorded in "baby books" or remembered by the mother, was considered the onset of the disease. This was usually 4-8 wk before the diagnosis was established in the first diabetic of the family, but less than $2 \mathrm{wk}$ for the other diabetics in the family.

Immunogenetic studies. 29 HLA antigens were determined with a standard two-stage dye exclusion microcytotoxicity test (16) by using a panel of 90 well-characterized antisera capable of detecting all defined HLA and most "W" specificities. HLA antigens were assigned without knowledge of disease. In the eight families in which the fathers were not available, one or both paternal haplotypes were deduced from those found in the rest of the family.

92 families tissue typed for bone marrow and kidney transplant or for HLA studies unrelated to diabetes or to antigens that have been associated with diabetes (A1, A2, $\mathrm{B} 8, \mathrm{~B} 18, \mathrm{BW} 15, \mathrm{BW} 40$ ) were used to determine the normal haplotype frequency in the Caucasian population in Minnesota. The parents of these nondiabetic families were used as controls. 343 typed haplotypes were counted in these control families.

Significance of associations was tested by chi-square analysis and $t$ tests for unpaired data.

\section{RESULTS}

FIG. 1. and Table I show, respectively, the pedigrees of the 24 kindreds studied, and the haplotypes in each family. 92 haplotypes were determined directly (87\%), 12 haplotypes were deduced, and 4 could not be determined, all of the latter in fathers. There were four haplotypes with one antigen blank (7\%), and there were four homozygotes for locus A, and five for locus B.

Tables II and III show the HLA haplotype concordance rates for diabetic-diabetic, diabetic-healthy, and healthy-healthy sib pairs in the 24 families. $55 \%$ of the diabetic pairs were concordant for both HLA haplotypes (expected 25\%), 40\% were concordant for one haplotype (expected 50\%), and 5\% were discordant for both haplotypes (expected 25\%). These values are 
D.D.

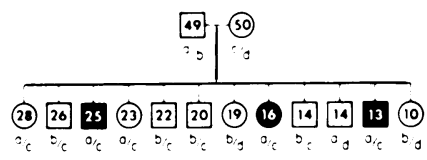

H.H.

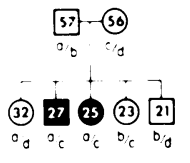

S.F.<smiles>[CH]=[Co]</smiles>
$2110 \%$
C.L.

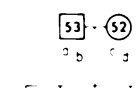

(23)
J.W.

舟, (3i)

1514
J.R.

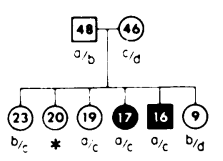

L.R.

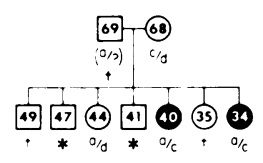

E.N.

(65) (5)

B.L. (39)-(3) $0 / 0, c / d$ 20 (18) 15

L.D.

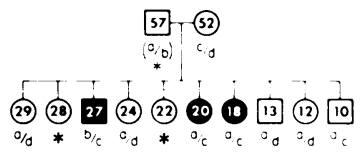

H.P.

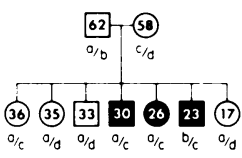

M.R.

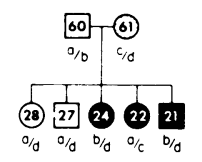

E.H.

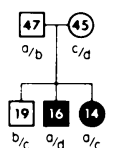

P. F.

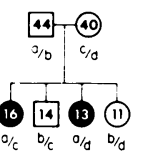

A.P.

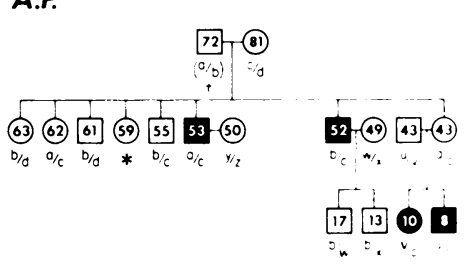

S.C.

P.D.

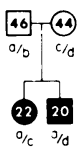

S.Rus.

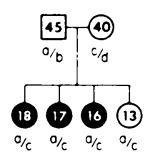

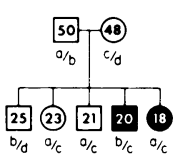

L.E.

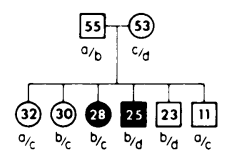

S.Ros.

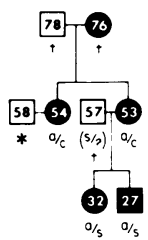

B.P.

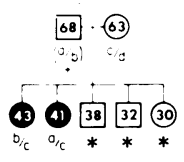

\section{W.P.}

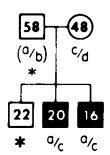

D.S.

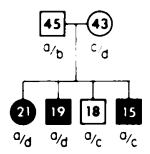

A.S.

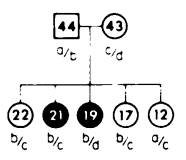

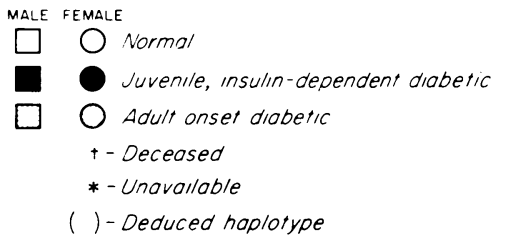

Figure 1 Pedigrees of 24 diabetic multiplex families. The paternal HLA haplotypes are designated by the letters $a$ and $b$ and the maternal haplotypes by the letters $c$ and $d$. When more than two generations were tissue typed, the letters u, v, w, x (family A. P.), and s (family S. Ros.) are used to designate the additional haplotypes.

significantly different from the expected values for all distributions of parental haplotypes $(P<0.001)$. The haplotype assortment followed mendelian segregation for the nondiabetic siblings.

Table IV shows the HLA haplotype concordance rate for our kindreds pooled with the 17 diabetic multiplex families reported from Great Britain (4). The pooled data is similar to that shown in Tables II and III, and the observed values are significantly different from those expected $(P<0.001) .10$ additional reported diabetic families (15) are not included here because a claimed high frequency of intra-HLA recombination ratio has not been confirmed by us.
However, our results would not be significantly changed by the addition of these families.

Table $\mathrm{V}$ shows the frequencies of haplotypes $\mathrm{Al}, \mathrm{B} 8$, $\mathrm{A} 1, \mathrm{BW} 15, \mathrm{~A} 2, \mathrm{BW} 15, \mathrm{~A} 2, \mathrm{BW} 40$, and A2,B8 in 92 control and 24 diabetic multiplex families. These specific haplotypes were studied because they showed a trend for increased frequency in the diabetic kindreds. There were appreciable increases in the frequency of haplotypes $\mathrm{A} 1, \mathrm{BW} 15, \mathrm{~A} 2, \mathrm{BW} 15, \mathrm{~A} 2, \mathrm{BW} 40$, and $\mathrm{A} 2, \mathrm{~B} 8$, but the numbers were too small for statistical analysis. Haplotype Al,B8 was not more frequent in the diabetic families, in spite of the recognized association of JIDD with B8 (3-5) and in some reports with Al (5). 
TABLE I

HLA Haplotypes in 24 Diabetic Multiplex Kindreds*

\begin{tabular}{|c|c|c|c|c|}
\hline \multirow[b]{2}{*}{ Families } & \multicolumn{2}{|c|}{ Father } & \multicolumn{2}{|c|}{ Mother } \\
\hline & a & $\mathbf{b}$ & c & d \\
\hline D. D. & $\mathrm{A} 2, \mathrm{BW} 40$ & A2,B7 & A3,BW35 & A28,BW35 \\
\hline H. H. & AW24,B8 & AW23,B14 & A1,B8 & A3,B7 \\
\hline S. F. & A2,B7 & A1,BW22 & A2,BW15 & A11,BW35 \\
\hline C. L. & AW32,BW14 & $\mathrm{A} 2, \mathrm{BW} 40$ & A1,B8 & A3,BW16 \\
\hline J. W. & (AW24,BW35) & $?$ & $\mathrm{~A} 1, \mathrm{~B} 12$ & AW25,B18 \\
\hline J. R. & A2,B5 & $\mathrm{A} 2, \mathrm{BW} 22$ & AW31,B12 & A1,BW35 \\
\hline L. R. $\$$ & (A28,BW15) & ? & A2,BW40 & $\mathrm{A} 2, \mathrm{BW} 21$ \\
\hline E. N. $\S$ & (AW25,B18) & $(\mathrm{A} 28, \mathrm{~B} 7)$ & A2,BW15 & A3,B27 \\
\hline B. L. & A2,BW15 & A11,B7 & $\mathrm{A} 11, \mathrm{BW} 22$ & Al,BW15 \\
\hline L. D. $\$$ & $(\mathrm{Al}, \mathrm{B} 8)$ & (A2,BW35) & AW24,BW40 & $\mathrm{A} 2, \mathrm{~B} 7$ \\
\hline H. P. & Al,B8 & A3,B5 & $\mathrm{A} 1, \mathrm{BW} 15$ & $\mathrm{~A} 2, \mathrm{BW} 15$ \\
\hline M. R. & $\mathrm{A} 2, \mathrm{BW} 40$ & A3,B7 & AW24,B18 & $\mathrm{A} 3, \mathrm{~B} 7$ \\
\hline E. H. & $\mathrm{A} 2, \mathrm{~B} 7$ & A3,BW15 & A2,B5 & A28,BW 15 \\
\hline P. F. & AW24,BW15 & $\mathrm{A} 3, \mathrm{x}$ & A2,B7 & $\mathrm{Al}, \mathrm{B} 8$ \\
\hline A. P. $\S$ & (x,BW35) & $(\mathrm{A} 2, \mathrm{x})$ & A1,BW16 & A3,BW15 \\
\hline S. C. & A2,B8 & $\mathrm{x}, \mathrm{BW} 40$ & A2,BW 15 & AW26,BW16 \\
\hline P. D. & A3,BW35 & A11,x & $\mathrm{A} 1, \mathrm{~B} 8$ & $\mathrm{~A} 2, \mathrm{~B} 7$ \\
\hline S. Rus. & A2,BW16 & AW24,B18 & A3,BW 15 & A29,B12 \\
\hline L. E. & A28,B5 & A11,B8 & A2,B12 & $\mathrm{A} 2, \mathrm{~B} 27$ \\
\hline S. Ros." & $?$ & $?$ & $?$ & $?$ \\
\hline B. P. $\S$ & $(\mathrm{A} 28, \mathrm{~B} 12)$ & $(A 29, x)$ & $\mathrm{A} 2, \mathrm{BW} 15$ & AW31,B12 \\
\hline W. P.t & $(\mathrm{A} 2, \mathrm{~B} 27)$ & $?$ & Al,B8 & AW26,B5 \\
\hline D. S. & $\mathrm{AW} 24, \mathrm{~B} 7$ & $\mathrm{x}, \mathrm{B} 12$ & A3,B 18 & AW31,BW40 \\
\hline A. $\mathrm{S}$. & $\mathrm{A} 1, \mathrm{~B} 8$ & A2,BW 15 & $\mathrm{~A} 2, \mathrm{~B} 12$ & $\mathrm{AW} 24, \mathrm{BW} 21$ \\
\hline
\end{tabular}

* See Fig. 1 for pedigrees.

\$ Deduced haplotypes, parent unavailable.

$\S$ Deduced haplotypes, parent deceased.

"The haplotypes known in this kindred could not be assigned to the deceased members of the first generation (see Fig. 1).

The frequencies of the various HLA A and B antigens in unrelated controls, diabetic sibs, and healthy sibs in the 24 diabetic multiplex kindreds are shown in Table VI. A1, AW24, B8, and BW15 showed an upward trend, and B5, B12, B13, and B14 showed a downward trend in the diabetic sibs. In the healthy sibs, upward trends were seen for antigens A1, A2, $\mathrm{A} 3, \mathrm{~B} 8$, and $\mathrm{BW} 15$, and downward trends for $\mathrm{B} 5, \mathrm{~B} 12$, and $\mathrm{B} 13$.

Table VII presents the frequency of the HLA anti-

TABLE II

HLA Haplotype Concordance for Diabetic and Healthy Sibs in 24 Diabetic Multiplex Kindreds (Two or More Diabetics in Each Sibship)

\begin{tabular}{|c|c|c|c|c|c|c|}
\hline \multirow{2}{*}{$\begin{array}{l}\text { Number of } \\
\text { concordant } \\
\text { haplotypes }\end{array}$} & \multicolumn{2}{|c|}{$\begin{array}{l}\text { Pairs of diabetic } \\
\text { sibs }(38)^{*}\end{array}$} & \multicolumn{2}{|c|}{$\begin{array}{l}\text { Pairs of diabetic- } \\
\text { healthy sibs (112)* }\end{array}$} & \multicolumn{2}{|c|}{$\begin{array}{c}\text { Pairs of healthy } \\
\text { sibs }(86)^{*}\end{array}$} \\
\hline & Found & Expected & Found & Expected & Found & Expected \\
\hline & \multicolumn{2}{|c|}{$\%$} & \multicolumn{2}{|c|}{$\%$} & \multicolumn{2}{|c|}{$\%$} \\
\hline 2 & $55(21)^{*}$ & $25(9.5)$ & $22(25)$ & $25(28)$ & $28(24)$ & $25(21.5)$ \\
\hline 1 & $40(15)$ & $50(19)$ & $51(57)$ & $50(56)$ & $48(41)$ & $50(43)$ \\
\hline 0 & $5(2)$ & $25(9.5)$ & $27(30)$ & $25(28)$ & $24(21)$ & $25(21.5)$ \\
\hline \multicolumn{7}{|c|}{$P<0.001 \not$} \\
\hline
\end{tabular}

* Number of pairs in parentheses.

\$ Chi-square analysis. All possibilities for shared haplotypes were counted (see Table III). 
TABLE III

Chi-Square Analysis of Data in Table II*

\begin{tabular}{|c|c|c|c|c|c|c|c|}
\hline $\begin{array}{l}\text { Number of parental } \\
\text { haplotypes present } \\
\text { in siblings }\end{array}$ & \multicolumn{2}{|c|}{$\begin{array}{c}\text { Distribution of parental } \\
\text { haplotypes in diabetic } \\
\text { sibs - families with two } \\
\text { diabetic siblings }\end{array}$} & \multicolumn{2}{|c|}{$\begin{array}{l}\text { Distribution of parental } \\
\text { haplotypes in diabetic } \\
\text { sibs - families with three } \\
\text { diabetic siblings }\end{array}$} & \multicolumn{2}{|c|}{ All families } & $x^{2}$ \\
\hline 2 & 10 & 4.5 & 2 & 0.375 & 12 & 4.875 & 10.41 \\
\hline 3 & 8 & 9.0 & 3 & 2.250 & 11 & 11.250 & 0.01 \\
\hline
\end{tabular}

* Chi-square analysis. The analysis is based on the determination of all possible distributions for the four parental haplotypes. Two siblings could have two, three, or four parental haplotypes between them with an expected frequency of 25 percent, 50 percent, and 25 percent $(1: 2: 1)$ for these distributions. Three siblings could have two, three, or four parental haplotypes between them, with an expected frequency of 6.25 percent, 37.5 percent, and 56.25 percent (1:6:9) for these distributions. The observed distributions for two sibs and for three sibs were compared to the expected and an $\chi^{2}$ was determined for the total distribution.

gens $\mathrm{A} 1, \mathrm{AW} 24, \mathrm{~B} 5, \mathrm{~B} 7, \mathrm{~B} 8, \mathrm{~B} 12, \mathrm{~B} 13, \mathrm{~B} 14, \mathrm{~B} 18$, and BW15 in a pool of our data and that of Cudworth and Woodrow (4). These antigens have shown an upward (A1, AW24, B8, and BW15) or a downward (B5, B12, $\mathrm{B} 13$, and B14) trend in our and/or the British data (4). Generally, these trends persisted after pooling the figures; however, because of probable bias from larger families, we did not perform statistical analyses of the data in Tables VI and VII.

Table VIII shows that the HLA identical diabetic sibs (concordant for two haplotypes) were significantly more concordant for the difference in age of onset of disease in years ( $3.9 \mathrm{vs} 7.3 \mathrm{yr} ; P<0.05)$ and difference in seasonal incidence in months $(1.8$ vs $3.2 \mathrm{mo} ; P$ $<0.025$ ) than the haplo-identical diabetic sibs (concordant for one haplotype). In the only family (M. R.) with one diabetic sib discordant for both haplotypes, the difference in age of onset of disease between the two diabetic HLA identical sibs, on the one hand (age of onset $1 \mathrm{yr}$ ), and the discordant diabetic sib, on the other hand (age of onset $13 \mathrm{yr}$ ), was most striking. This type of analysis did not elicit significant differences for family history of disease, frequency of vascular concomitants, or sex of patients.

Fig. 2 depicts the distribution of HLA identical and HLA haploidentical diabetic sibs according to the month in which the disease had started. The families L. D., H. P., and D. S. were excluded from this analysis because they included both HLA identical and haploidentical diabetic sibs. The HLA identical diabetics had the onset of diabetes more frequently in the winter months of November through April (78\%) than the haploidentical diabetic sibs $(21 \%)$.

Table IX compares HLA identical and haploidentical diabetic sibs, also excluding families L. D., H. P., and D. S. The only difference detected between the two groups was a high frequency of haplotypes Al, B8 ( 44 vs $8 \%$ ), and A2,BW40 (16 vs $0 \%$ ) in the HLA identical diabetics; only the former difference showed marginal statistical significance. Age, sex, history of infection before the onset of diabetes, age at onset, and family history of diabetes were the same for both groups.

The diabetics of the families in which the segregation of the HLA haplotype associated with diabetes suggested autosomal dominant inheritance (S. Ros. and A. P.) did not show any distinguishing clinical features.

\section{DISCUSSION}

Because JIDD is probably a heterogeneous disease. and studies of the HLA system in man have prover useful in the analysis of disease heterogeneity (11). we decided to study HLA genotypes in kindreds with

\section{TABLE IV}

HLA Haplotype Concordance for Diabetic Sibs in 41 Diabetic Multiplex Kindreds*

\begin{tabular}{|c|c|c|}
\hline \multirow{2}{*}{$\begin{array}{c}\text { Number of concordant } \\
\text { haplotypes }\end{array}$} & \multicolumn{2}{|c|}{ Pairs of diabetic sibs (62) 1} \\
\hline & Found & Expected \\
\hline & \multicolumn{2}{|c|}{$\%$} \\
\hline 2 & $48(33) \downarrow$ & $25(15.5)$ \\
\hline 1 & $46(25)$ & $50(31)$ \\
\hline \multirow[t]{2}{*}{0} & $6(4)$ & $25(15.5)$ \\
\hline & \multicolumn{2}{|c|}{$\begin{array}{c}P<0.001 \\
\left(\chi^{2}=29.45 ; \mathrm{df}=2\right) \S\end{array}$} \\
\hline
\end{tabular}

* Pool of our and Cudworth and Woodrow's data (4).

$\$$ Number of pairs in parentheses.

$\$$ Chi-square analysis. $P$ value expresses difference from expected distribution; df, degree of freedom. 
TABLE V

HLA Haplotype Frequencies in 92 Control and 24 Diabetic Multiplex Kindreds with Two or More Diabetic Sibs

\begin{tabular}{|c|c|c|c|c|c|c|c|c|c|c|}
\hline & \multicolumn{2}{|c|}{ A1,B8 } & \multicolumn{2}{|c|}{ Al,BW15 } & \multicolumn{2}{|c|}{ A2,BW15 } & \multicolumn{2}{|c|}{$\mathrm{A} 2, \mathrm{BW} 40$} & \multicolumn{2}{|c|}{ A2,B8 } \\
\hline & no. & $\%$ & no. & $\%$ & no. & $\%$ & no. & $\%$ & no. & $\%$ \\
\hline $\begin{array}{l}\text { Parents - control } \\
\quad(343) * \ddagger\end{array}$ & 31 & 9.0 & 1 & 0.2 & 12 & 3.4 & 7 & 2.0 & 1 & 0.2 \\
\hline $\begin{array}{l}\text { Parents - diabetic } \\
\quad(96) \downarrow\end{array}$ & 9 & 9.3 & 2 & 2.0 & 7 & 7.2 & 4 & 4.1 & 2 & 2.0 \\
\hline
\end{tabular}

* Number of haplotypes available.

$\$$ Includes deduced haplotypes (see Table I).

two or more diabetic children in which genetic homogeneity is more likely.

Ours is the first study of HLA haplotypes in complete sibships of JIDD multiplex families and is an important extension of previous reports in that it allows a comparison between diabetic and nondiabetic siblings. This comparison is important because unaffected siblings can be useful controls in a sibship investigation by minimizing spurious influences from population stratification and equalizing environmental and genetic variation. We found a statistically significant association between the sharing of an identical haplotype and the development of JIDD within a sibship, thus confirming the findings of Cudworth and Woodrow (4). Furthermore, greater than half of the diabetics in these sibships with two or more diabetics were HLA identical (i.e. both haplotypes identi- cal). The healthy siblings did not have an alteration in their haplotype assortment, either when compared with the diabetic sibs or with the other healthy sibs, and haplotype segregation appeared mendelian in all families.

The increased frequency of HLA identity among diabetic siblings, and the concomitant reduction in the number with both haplotypes different, suggest that there may be one or more genes influencing the development of diabetes that are closely associated with the HLA system. The single case of a diabetic sharing no haplotype with her diabetic sibs (family M. R.) could be the result of crossover between the diabetic gene and the HLA haplotype. However, two crossovers would be necessary, and this is unlikely. Alternatively, this sib may have a different type of diabetes, or the disease may be unrelated to HLA in this family.

TABLE VI

Frequency of HLA Antigens in Unrelated Controls, and Diabetic and Healthy Sibs of 24 Diabetic Multiplex Kindreds

\begin{tabular}{|c|c|c|c|c|c|c|c|c|}
\hline Antigen & $\frac{\begin{array}{c}\text { Controls } \\
(217)^{*}\end{array}}{\%}$ & $\begin{array}{c}\begin{array}{c}\text { Diabetic sibs } \\
(58)^{*}\end{array} \\
\%\end{array}$ & $\begin{array}{c}\begin{array}{c}\text { Healthy sibs } \\
(53)^{*}\end{array} \\
\%\end{array}$ & \multicolumn{2}{|c|}{ Antigen } & $\begin{array}{c}\begin{array}{c}\text { Controls } \\
(217)^{*}\end{array} \\
\%\end{array}$ & $\begin{array}{c}\begin{array}{c}\text { Diabetic sibs } \\
(58)^{*}\end{array} \\
\%\end{array}$ & $\begin{array}{c}\begin{array}{c}\text { Healthy sibs } \\
(53)^{*}\end{array} \\
\%\end{array}$ \\
\hline Locus A: 1 & 27 & 34 & 36 & Locus & B: 5 & 13 & 7 & 8 \\
\hline 2 & 55 & 62 & 74 & & 7 & 26 & 22 & 32 \\
\hline 3 & 28 & 22 & 42 & & 8 & 21 & 31 & 32 \\
\hline 11 & 10 & 3 & 6 & & 12 & 30 & 9 & 17 \\
\hline 28 & 7 & 9 & 11 & & 13 & 7 & 0 & 0 \\
\hline 29 & 4 & 0 & 1 & & 14 & 6 & 0 & 4 \\
\hline W23 & 3 & 0 & 4 & & 18 & 6 & 9 & 6 \\
\hline W24 & 15 & 31 & 8 & & 27 & 5 & 10 & 6 \\
\hline W25 & 5 & 3 & 2 & & W15 & 17 & 36 & 25 \\
\hline W26 & 9 & 0 & 0 & & W16 & 7 & 14 & 13 \\
\hline W30 & 4 & 0 & 0 & & W17 & 5 & 0 & 0 \\
\hline W31 & 3 & 7 & 4 & & W21 & 6 & 0 & 2 \\
\hline W32 & 6 & 0 & 2 & & W22 & 1 & 0 & 6 \\
\hline W33 & 1 & 0 & 0 & & W35 & 14 & 17 & 25 \\
\hline & & & & & W40 & 18 & 24 & 15 \\
\hline
\end{tabular}

* Number of subjects studied in parentheses. 
TABLE VII

Frequency of HLA Antigens in 95 Diabetic Sibs from 41 Diabetic Multiplex Kindreds*

\begin{tabular}{lcrr}
\hline Antigen & $\begin{array}{c}\text { Controls } \\
(217) \text { f }\end{array}$ & \multicolumn{2}{c}{ Diabetic sibs (95)‡ } \\
\hline & $\%$ & no. & $\%$ \\
A1 & 27 & 31 & 33 \\
AW24 & 15 & 18 & 19 \\
B5 & 13 & 9 & 9 \\
B7 & 26 & 17 & 18 \\
B8 & 21 & 35 & 37 \\
B12 & 30 & 17 & 18 \\
B13 & 7 & 0 & 0 \\
B14 & 6 & 4 & 4 \\
B18 & 6 & 13 & 14 \\
BW15 & 17 & 29 & 31 \\
\hline
\end{tabular}

* Includes our 24 kindreds and 17 from Great Britain (4). $\$$ Number of subjects studied in parentheses.

Furthermore, the development of diabetes in HLA identical siblings more often in the winter months, and the development of diabetes in one-haplotype identical siblings more often in the summer months, suggests heterogeneity that may be on a genetic basis. One explanation for these observations is that there is a locus (or loci) located close to the loci of the HLA system, whose alleles control the development of diabetes by regulating the response to the environmental stimuli, that is, a diabetes response gene(s). If this is the case, the exact genetic mechanism for regulation of this response is not clear.

One possibility is that there are two different genetic mechanisms active in these kindreds, with a dominant response gene in those families with one haplotype identity and a recessive response gene in those with HLA identity. Pincus and White (17) were the first to propose an autosomal recessive inheritance for JIDD,

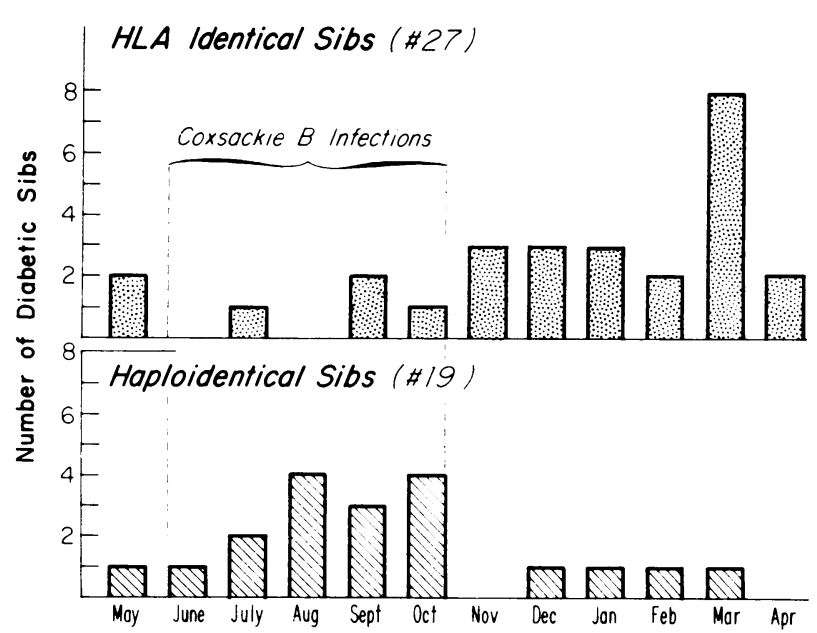

FIGURE 2 Month of onset of symptoms of diabetes in diabetics of families with two or three diabetic sibs. Months during which Coxsackie B infections in Minnesota are most common are also shown. Diabetes developed more frequently in the winter months in HLA identical diabetic sibs.

and many authors have argued in favor of this mode of inheritance (1); however, a considerable amount of published data is incompatible with a recessive mechanism (1). Evidence against the presence of a dominant gene in the families reported here is the fact that none of the parents in the one-haplotype identical sibships had diabetes. However, families S. Ros. and A. P. suggest dominant inheritance. In family S. Ros., three consecutive generations are affected, and the diabetic trait seems to segregate with haplotype a. In family A. P., two generations are affected, and haplotype c seems to segregate with diabetes. However, three subjects, including the parent of two diabetics, carry this haplotype and are not overtly diabetic; therefore, incomplete penetrance would have to be postulated in this family.

TABLE VIII

Intra-HLA Pair Concordance Analysis for Onset and Seasonal Incidence of Disease in the HLA Identical vs. Haploidentical Diabetic Sibs from 24 Diabetic Multiplex Kindreds

\begin{tabular}{lcccc}
\hline & \multicolumn{4}{c}{ Pairs } \\
\cline { 2 - 5 } & $\begin{array}{c}\text { HLA identical (20)* } \\
\text { (concordant for } \\
\text { two haplotypes) }\end{array}$ & $\begin{array}{c}\text { Haploidentical (15)* } \\
\text { (concordant for } \\
\text { one haplotype) }\end{array}$ & $t 1$ & $P$ \\
\hline $\begin{array}{c}\text { Difference in age of } \\
\text { onset in years }\end{array}$ & $3.90 \pm 0.40$ & $7.33 \pm 1.85$ & 2.053 & $<0.05$ \\
$\begin{array}{c}\text { Difference in seasonal } \\
\text { incidence in months }\end{array}$ & $1.85 \pm 0.33$ & $3.20 \pm 0.47$ & 2.435 & $<0.025$ \\
\hline
\end{tabular}

All values as mean \pm SEM.

* Number of subjects in parentheses.

$\$$ Student's $t$ test for unpaired data. 
TABLE IX

Clinical Profile and Haplotypes of HLA Identical and Haploidentical Diabetic Sibs

\begin{tabular}{lccc}
\hline & $\begin{array}{c}\text { HLA } \\
\text { identical } \\
\text { sibs } \\
(27)^{*}\end{array}$ & $\begin{array}{c}\text { Haploidentical } \\
\text { sibs } \\
(19)^{*}\end{array}$ & $\mathrm{P}$ \\
\hline Age at onset of diabetes (years) & $10.1 \pm 1.81$ & $11.3 \pm 4.2 !$ & $\mathrm{NS}$ \\
Sex (males) & $47 \%$ & $53 \%$ & $\mathrm{NS}$ \\
Infections before onset of diabetes & $25 \%$ & $16 \%$ & $\mathrm{NS}$ \\
Family history of diabetes $\$$ & $79 \%$ & $85 \%$ & $\mathrm{NS}$ \\
Haplotype A1,B8 & $44 \%$ & $8 \%$ & $<0.05^{* *}$ \\
Haplotype A2,BW40 & $16 \%$ & $0 \%$ & $\mathrm{NS}$ \\
\hline
\end{tabular}

* Number of subjects in parentheses.

1 Mean is \pm SD.

$\$$ Other than the diabetic sibs.

"Present in 15 kindreds.

9 Present in nine kindreds.

** $\chi^{2}=4.316$

Against a two-gene model is the fact that diabetic siblings that were HLA identical and diabetic siblings that were only one-haplotype identical were found within the same sibship. It seems unlikely that two separate diabetes response genes would be segregating in the same family.

Another possibility is that there is one diabetes response gene segregating in these families and that it is expressed codominantly with the normal allele from this locus. For those individuals with a single copy of this abnormal gene, the environmental stimuli must be great to produce diabetes and a number of individuals carrying this gene will escape its development. When an individual is homozygous for this diabetes response gene, it is more likely that diabetes will develop. A variation of this mechanism would be that there are a number of diabetic alleles at the diabetes response locus, and an affected individual could be heterozygous and carry two separate diabetic alleles. Multiple allelism has been suggested as one explanation of genetic heterogeneity (18). For both situations, the clinical expression for the diabetes is the same after onset of the disease. The data from the families reported here fit this explanation best. Higher concordance for age of onset and seasonal incidence of the disease in the HLA identical, as compared with the haploidentical diabetic sibs, is compatible with this interpretation. There are many nondiabetic siblings that share one haplotype but few that share both. Evidence against this genetic mechanism is the fact that none of the parents in these 24 families is diabetic; however, it is possible that the parents escaped diabetes because of the lack of an appropriate environmental stimulus, whereas a strong stimulus occurred with the diabetic offspring. The same stimulus may no longer affect the parents at the time the offspring are affected. An additional possibility is that the parents in these families may have mild, undetected diabetes. Most of them have not had glucose tolerance tests.

Inasmuch as there is a $50 \%$ chance of one-haplotype identity for any sib-pair, the occurrence of HLA identity in $50 \%$ of the pairs could be the result of an abnormally high frequency of one-haplotype identity. This would be compatible with the single-dose gene effect.

The HLA data presented here is compatible with several other lines of evidence $(1,2)$ strongly suggesting genetic heterogeneity of JIDD. Many of the difficulties encountered in this and other studies attempting to relate HLA haplotypes and antigens to the JIDD phenotype may be due to the existence of one or several types of HLA-unrelated JIDD.

Preliminary studies of eight nondiabetic siblings HLA identical with their diabetic sibs revealed that five have latent diabetes (abnormal cortisone-primed glucose tolerance tests). This finding, if confirmed, would suggest that the diabetes response gene, even when present in double dose, does not determine full expression of diabetes, and an additional environmental diabetogenic factor may be required. The tendency for HLA identical siblings to develop diabetes in the winter and for one-haplotype identical siblings to develop it in the summer may be related to seasonal environmental stimuli that interact differently with diabetes response genes that are present in a single or double dose.

Recent evidence suggests that environmental factors play a major role in the development of JIDD in genetically susceptible individuals. Some cases of JIDD in humans (19) and hyperglycemia in certain strains of mice $(20,21)$ are thought to be virus induced. There is a marked variation in the incidence of JIDD in families with both parents diabetic (22). Abnormal humoral and cell-mediated immune function has been found in some but not all JIDD patients studied (23). The concordance rate for JIDD in identical twins is only about $50 \%(2)$.

Epidemiologic studies in Great Britain (24) and the United States (25) have shown that JIDD starts somewhat more frequently in the winter and fall. Data from the register of newly diagnosed diabetic children in Great Britain (26), including more than 2,000 cases, have confirmed a seasonal variation in incidence in children 5-15 yr of age with peaks in the fall and winter. No seasonal variation in incidence was seen in children age 0-4 yr at onset of diabetes. Epidemiologic studies searching for relationships between HLA antigens and month of onset of diabetes have given conflicting results $(27,28)$. In addition, evidence of geographical variations in incidence from year to year, and the occurrence of diabetes almost simultaneously in sibs of different ages within the same kindred were noted (26).

Of the various environmental factors considered, 
viral infections seem most important. Retrospective studies comparing early diabetics with older diabetics and nondiabetics found elevated Coxsackie B4 antibody titers in the former group (19). Susceptibilities to Coxsackie B experimental diabetes in C57BL/Ks mice (20), and to encephalomyocarditis-M virus diabetes in DBA/2 and $\mathrm{C} 3 \mathrm{H}$ mice (21), are genetically determined.

The seasonal peak of Coxsackie $B$ infections in Minnesota encompasses the months of June through October. ${ }^{2}$ If a lag period intervened between the viral infection and the onset of diabetes, our data would be compatible with a pathogenetic role of Coxsackie B, or other virus with the same infective seasonal pattern, in HLA identical diabetics.

The mechanism by which a diabetes response gene would influence the development of viral diabetes is unknown. The diabetes response gene may be an immune response gene that controls the immunologic response to viral antigens. A defective immune response gene has been suggested as playing a role in human diabetes (4).

Mononuclear cell infiltration of islets in early JIDD (23) and in experimental viral diabetes (29), cell-mediated immunity abnormalities in about $30 \%$ of the JIDD patients studied (23), and islet cell antibodies in $80 \%$ of B8-positive JIDD patients early in the course of the disease (30), all suggest an underlying immune abnormality.

An immune response gene that controls T-cell function may be important in diabetes, as shown by the fact that athymic mice from strains that are normally susceptible to viral diabetes develop neither mononuclear cell infiltration nor hyperglycemia after an adequate viral challenge, although the viruses do colonize their islets (29).

If the diabetes response gene controls immune response, then it appear to be closely associated with the HLA system. JIDD in diabetic populations has been associated with HLA B8 (3-5) and BW15 $(3,4,6)$, and the relative risk for diabetes in a subject carrying both antigens has been said to be 10-fold that of individuals without those antigens (11). As shown in Table $\mathrm{V}$, antigens B8 and BW15 showed an upward trend as reported earlier (3-5). Some of the haplotypes shown in Table $\mathrm{V}$ seemed increased in diabetic families, but the numbers were two small for statistical analysis. Many other haplotypes were associated with JIDD in these families, however, and it seems unlikely that any specific HLA antigen plays a direct role in the development of diabetes.

It is possible that the JIDD present in our families is not representative of all or even most cases of JIDD,

\footnotetext{
${ }^{2}$ Balfour, H. Personal communication.
}

which are often seen as isolated cases in their respective families.

It has been claimed in preliminary reports on both population (31) and family (32) studies that the frequency of HLA antigen B7 is significantly decreased among JIDD patients. However, the family study (32) that did not specify whether all the previously known diabetics were insulin-dependent, apparently included in the analysis relatives of the diabetics with abnormal 2-h postprandial glucose tolerance but not overt diabetes. These data have been interpreted as suggesting that B7 is associated with a genetic protective factor for diabetes. Our family data show no disturbance of B7 frequency in the diabetic sibs, although other B alleles, especially B5, B12, B13, and B14, showed a downward trend. It is possible that this simply reflects the higher frequency of alleles B8 and BW15 in this population.

An intra-HLA recombination rate of $16 \%$ (both $\mathrm{A} / \mathrm{B}$ and $B / D$ ) has been reported in both diabetic and nondiabetic sibs in a study of 10 diabetic families that included a total of 37 siblings (15). This frequency of recombination is at least 100 -fold higher than that expected, and our data do not support these findings. In the 42 kindreds reported here and elsewhere (4), including at least 187 siblings, only one definitive $\mathrm{A} / \mathrm{B}$ HLA crossover in Cudworth and Woodrow's kindreds (4) was observed, resulting in a recombination frequency of $<1 \%$.

In conclusion, our HLA studies of diabetic multiplex families confirm the marked genetic heterogeneity of JIDD, seen even among diabetic sibs. Although the data described here are compatible with the existence of one or more diabetes response genes associated with the HLA, it is possible that in some of the families studied the association of diabetes with HLA is fortuitous.

\section{ACKNOWLEDGMENTS}

We wish to thank V. Elving Anderson and Kathleen M. Keenan for their kind assistance in the statistical analysis. We are also grateful to the family members who kindly cooperated in these studies. Dr. F. C. Goetz has always been a source of great encouragement and support.

This work was supported by Clinical Center grant CA 19589-01, General Clinical Research Centers Program (RR-400), the Division of Research Resources, National Institutes of Health, and U. S. Public Health Services grants HL-06314, 1R01HD08145, National Institute of Allergy and Infectious Diseases 72-54 contract.

\section{REFERENCES}

1. Rimoin, D. L. 1971. Inheritance in diabetes mellitus. Med. Clin. N. Am. 55: 807-819.

2. Nelson, P. G., D. A. Pyke, A. G. Cudworth, T. C. Woodrow, and A. Batchelor. 1975. Histocompatibility antigens in diabetic identical twins. Lancet. II: 193-194.

3. Nerup, J., P. Platz, O. O. Anderson, M. Christy, J. 
Lyngsoe, J. Poulsen, L. Ryder, S. Nielsen, M. Thomsen, and A. Svejgaard. 1974. HL-A antigens in diabetes mellitus. Lancet. II: 864-866.

4. Cudworth, A. G., and J. C. Woodrow. 1975. Evidence for HLA-linked genes in "juvenile" diabetes mellitus. $B r$. Med.J. 3: 133-135.

5. Barbosa, J., H. Noreen, F. C. Goetz, R. Simmons, A. Deleiva, J. Najarian, and E. J. Yunis. 1976. Histocompatibility (HLA) antigens and diabetic microangiopathy. Tissue Antigens. 7: 283-288.

6. Singal, D. P., and M. A. Blajchman. 1973. Histocompatibility (HLA) antigens, lymphocytotoxic antibodies and tissue antibodies in patients with diabetes mellitus. Diabetes. 22: 429-432.

7. Schernthaner, G., W. Mayr, M. Pacher, H. Ludwig, W. Erd, and M. Eibl. 1975. HLA8, W15, and T3 in juvenile onset diabetes mellitus. Horm. Metab. Res. 7: 521-522.

8. Thomsen, M., P. Platz, O. O. Anderson, M. Christy, J. Lyngsoe, J. Nerup, K. Rasmussen, L. Ryder, S. Nielsen, and A. Svejgaard. 1975. MLC typing in juvenile diabetes mellitus and idiopathic Addison's disease. Transplant. Rev. 22: 125-147.

9. Barbosa, J., R. King, F. Goetz, H. Noreen, and E. J. Yunis. 1977. Histocompatibility (HLA) antigens in a kindred with maturity-onset type of diabetes in the young. Arch. Intern. Med. In press.

10. Pike, D., and P. Nelson. 1976. Genetic diabetes not linked to the HLA locus. Br. Med. J. 1: 196-197.

11. Svejgaard, A., P. Platz, and L. Ryder. 1975. HLA and disease associations: a survey. Transplant. Rev. 22: 3-43.

12. Ludvigsson, J., J. Safvenberg, and L. Heding. 1977. HLA types, C-peptide and insulin antibodies in juvenile diabetes. Diabetologia. 13: 13-17.

13. Jansen, F., J. Bertrams, D. Gruneklee, H. Drost, H. Reis, H. Bever, E. Kuwert, F. Gries, and E. Altrock. 1975. Genetic association of insulin antibody production with histocompatibility (HLA) antigens in diabetics. Diabetologia. 11: 352-353. (Abstr.)

14. Ludvigsson, J., and L. Heding. 1976. C-peptide in children with juvenile diabetes: a preliminary report. Diabetologia. 12: 627-630.

15. Rubinstein, P., M. Suciu-Foca, J. F. Nicholson, M. Fotino, A. Molinaro, L. Harisiadis, M. A. Hardy, K. Reemtsma, and F. H. Allen. 1976. The HLA system in families of patients with juvenile diabetes mellitus. J. Exp. Med. 143: $1277-1282$.

16. Amos, D. B., W. Bashir, W. Boyle, M. MacQueen, and A. Tiilikainen. 1969. A simple microcytotoxicity test. Transplantation. 7: 220-223.
17. Pincus, G., and P. White. 1933. On the inheritance of diabetes mellitus. I. An analysis of 675 family histories. Am. J. Med. Sci. 186: 1-19.

18. Harris, H. 1975. Genetic heterogeneity in inherited disease. J. Clin. Pathol. (Lond.). 27: 32-37.

19. Steinke, J., and K. W. Taylor. 1974. Viruses and the etiology of diabetes. Diabetes. 23: 631-633.

20. Webb, S. R., R. M. Loria, G. E. Madge, and S. Kibrick. 1976. Susceptibility of mice to group B Coxsackie virus is influenced by the diabetic gene. J. Exp. Med. 143: 1239-1242.

21. Craighead, J. E., and D. A. Higgins. 1974. Genetic influences affecting the occurrence of a diabetes mellituslike disease in mice infected with the EMC virus. J. Exp. Med. 139: 414-426.

22. Tattersall, R. B., and S. S. Fajans. 1975. Prevalence of diabetes and glucose intolerance in 199 offspring of thirtyseven conjugal diabetic parents. Diabetes. 24: 452-462.

23. MacCuish, A. C., and W. J. Irvine. 1975. Autoimmunological aspects of diabetes mellitus. Clin. Endocrinol. Metab. 4: 435-471.

24. Gamble, D. R., and K. W. Taylor. 1973. Coxsackie virus and diabetes mellitus. Br. Med. J. 4: 260-262.

25. Hafezi, V., D. Zeidner, M. Kotoyan, and D. R. MacMillan. 1976. Seasonal variation in the onset of juvenile diabetes mellitus. Clin. Res. 24: 66A. (Abstr.)

26. Bloom, A., R. M. Hayes, and D. R. Gamble. 1975. Register of newly diagnosed diabetic children. Br. Med. J. 3: 580-583.

27. Barbosa, J., H. Noreen, F. Goetz, R. Simmons, J. Najarian, and E. J. Yunis. 1976. Juvenile diabetes and viruses. Lancet. I: 371.

28. Rolles, C., P. Rayner, and P. MacKintosh. 1975. Etiology of juvenile diabetes. Lancet. II: 230.

29. Buschard, K., J. Rygaard, and E. Lund. 1976. The inability of a diabetogenic virus to induce diabetes mellitus in athymic (nude) mice. Acta Pathol. Microbiol. Scand. 84: 299-303.

30. Morris, P. J., H. Vaughan, W. J. Irvine, C. J. McCallum, R. S. Gray, C. J. Campbell, L. J. Duncan, and J. W. Farquhar. 1976. HLA and pancreatic islet cell antibodies in diabetes. Lancet. II: 652-653.

31. Ludwig, H., G. Schernthaner, and W. R. Mayr. 1976. Is HLA B7 a marker associated with a protective gene in juvenile-onset diabetes mellitus? N. Engl. J. Med. 294: 1066.

32. Van de Putte, I., C. Vermylen, P. Decraene, R. Vlietinck, and H. Berghe. 1976. Segregation of HLA B7 in juvenileonset diabetes mellitus. Lancet. II: 251. 